\title{
RESEARCH ON THE CONSTRUCTION OF CURRICULUM SYSTEM OF SINO-FOREIGN COOPERATIVE PROGRAMS FROM THE PERSPECTIVE OF CULTURAL ADAPTATION --- A CASE STUDY OF SINO-AMERICAN NURSING PROGRAM OF HUBEI UNIVERSITY OF CHINESE MEDICINE
}

\author{
Xie Tingting \\ School of Foreign Languages of Hubei University of Chinese Medicine, No. 1 West Huangjia Lake Road, Wuhan, China.
}

This is an open access article distributed under the Creative Commons Attribution License, which permits unrestricted use, distribution, and reproduction in any medium, provided the original work is properlv cited

\section{ARTICLE DETAILS}

Article History:

Received 12 November 2017 Accepted 12 December 2017 Available online 1 January 2018

\begin{abstract}
The trend of economic globalization promotes the development of education. The promotion of Sino-foreign cooperative programs is the essential means to speed up the internationalization of Chinese higher education. From the angle of cultural adaption, this paper makes a detailed case study of the Sino-American Nursing Program of Hubei University of Chinese Medicine and Winston Salem State University. It focuses on the curriculum system of the program, from its setting to the implementation. A survey is conducted among students and teachers. Based on the results, the major problems of the curriculum system are discussed. Then the causes of the problems are analyzed in brief. They are related to culture adaptation to a certain extent. In the end, some suggestions to improve the curriculum system of Sino-US cooperative program are put forward. Hopefully, this paper will shed some light on the improvement of Sino-foreign cooperative undergraduate programs.
\end{abstract}

\section{KEYWORDS}

Cultural adaptation; Sino - foreign cooperative program; Curriculum system; Education.

\section{INTRODUCTION}

Our world is entering the process of globalization. The communication, collision and integration between different cultures will become more frequent and deeper. No country can avoid the influence of this trend. Therefore, Sino-foreign cooperative education is a possible way of communication and interaction between China and other countries [1]. In order to cultivate innovative and well-rounded talents, we must learn from foreign advanced educational concepts and teaching experiences, adjust the direction and objectives of running schools, and make up for the shortage of higher education resources in our country. How to adapt to the international trend of human resources development and meet the needs of cultural, economic and social development against the background cultural shock and intersection becomes an important issue in the Sinoforeign cooperative programs.

\section{CULTURAL ADAPTION AND CURRICULUM}

Cultural adaptation is a basic concept that reflects cultural characteristics and cultural functions. It mainly refers to the adaptation of culture to the environment and also to the mutual adaptation of various parts of culture. Redfield and Herskovitz proposed in 1936 that "when people from different cultural groups engage in continuous direct contact, changes in the original cultural types of one or both parties are called cultural adaptation [2]. To probe into the curriculum of Sino-foreign cooperative programs from the angle of cultural adaptation is to study the curriculum from a completely new angle, which is in line with the reality of social and cultural diversity at present.

The function of the curriculum is to cultivate students' ability, which should reflect the social demand for talents as well. Therefore, to deal with the relationship among the society, the students and the curriculum in a multicultural environment effectively is the common goal of education. Culture and curriculum is a unity. Culture would influence the setting-up of curriculum and provide help for its development. And the curriculum would inherit and transmit culture. So, the design and management of curriculum must take the cultural factors into account. As for Sino-foreign cooperative education programs, the key point of its curriculum is to coordinate relationships between different cultures. How to adhere to the local characteristics on the basis of organic integration of Chinese and foreign culture, how to balance the different requirements of China with foreign courses, how to make the Sino-foreign cooperative programs to meet the employment needs of both domestic and abroad, all the above problems are the challenges facing the cooperative universities. In fact, it is a problem of cultural conflict.

\section{CURRICULUM SYSTEM OF THE SINO-AMERICAN NURSING} PROGRAM OF HUBEI UNIVERSITY OF CHINESE MEDICINE

The Nursing Program is run by Hubei University of Chinese Medicine (HUCM) and Winston Salem State University (WSSU). The cultivating model is 3 plus 1.5 years. That is, students learn the basic and professional courses in China for three years. When they finish those courses, if their GPA meet the requirements of WSSU, they can go abroad for further studies. And if they successfully complete their courses and related examinations in the United States, they can obtain a Bachelor of Science degree from WSSU. On the basis of this model, the two sides worked out the curriculum arrangement of nursing program. After negotiating for several times, a final curriculum was decided. From the perspective of curriculum structure, it mainly includes general courses and professional courses.

Chinese students are required to complete eighteen general courses: English, Mathematics, Chemistry and so on. It covers a wide range of subjects, including social sciences and natural sciences. Students are encouraged to master basic mathematical skills, improve written and oral communication skills, enrich knowledge of history and culture, and strengthen their critical reading and thinking ability. At the same time, physical and mental health should be ensured. These are the sparkles of foreign general education. It aims to expand students' horizons and to promote students' comprehensive development in intelligence, physical strength, morality and emotion as well. 
As for the professional courses, basically there are basic professional courses and core professional courses. There are some common courses between HUCM and WSSU, such as Pediatric Care, Adult Care and so forth. However, after careful study of the course syllabuses, the teaching staff found that the names seemed to be the same, but the contents were somewhat different. In order to meet the requirements of WSSU, the Chinese faculty made great efforts to adjust the conventional courses. Besides, there are some new courses, such as Health Assessment, Developmental Psychology. They are added to the curriculum, which means some teachers would prepare for the new courses. What's more, to retain the Chinese characteristics, some special courses, such as Nutrition and Diet, Basic Nursing of Traditional Chinese Medicine are kept. At the same time, the course, Nursing English, is also added for the students who intend to go abroad improve their communication skills.

\section{IMPLEMENTATION OF THE NURSING PROGRAM AND ANALYSIS OF ITS PROBLEMS}

Since the first enrollment in 2011, the program has been carried out for seven years. Generally speaking, it is going on well. Some graduates went abroad to continue their studies, while others were employed at home. Whether they are satisfied with the program curriculum, and whether the existing curriculum can help them find jobs or adapt to the life in the United States are the important basis for the program betterment. In order to analyze the problems objectively, a questionnaire survey on the curriculum conducted, the project faculty were interviewed. Base on the statistics and opinions, this paper attempts to analyze the curriculum of Sino-American cooperative programs from the angle of cultural adaptation.

According to the results of questionnaire and interview, a majority of students agree that the general courses were good, but the contents could be enriched. Most students who work at home think the professional courses are useful for their work, but they want more practical training. But for the ones who study at WSSU, they report that professional courses they learn at HUCM are not tightly coherent with those at WSSU. They even have to spend a lot of time to learn the same courses again. Furthermore, due to the lack of the awareness of cultural communication, it takes them quite long to adapt to the new environment in the United States. The teachers encounter some difficulties in teaching as well. As far as they have concerned, the actual situation of China hasn't been considered thoroughly. In general, the curriculum problems in the Sino-American Nursing Program belongs to cultural adaptation field.

\subsection{Cultural Adaptation of the Curriculum}

As a new concept of education, general education pays more attention to the cultivation and improvement of humanistic spirit and the continuous improvement and perfection of personality. It helps to cultivate wellrounded talents, namely, students should pay attention to the mastery of professional knowledge and practical skills as well as the mold of their morality, personality and values [3]. In the initial stage of cooperation, the general courses in curriculum system were basically set according to the requirements of foreign universities. Those general courses are typical in foreign education, which are completely absent in the Chinese nursing education. So, it would be beneficial for Chinese students.

According to the feedback of the students' survey, most students think that the general education curriculum is wide in range and rich in content and has a positive effect on the improvement of individuals' basic ability, especially their knowledge of social sciences. However, students also say that many course names are similar to those of foreign countries, but the content is completely different. It creates a great obstacle to their followup study. Why did this happen? Because when the courses were introduced, some courses only retained the names, but the actual content was adjusted according to the existing faculty capacity of HUCM. For example, Music Appreciation and Art Appreciation, the original intention was to introduce the basic knowledge of Western music and art, but the Chinese side changed them into traditional Chinese music and art appreciation. Like General Psychology, it should be introduced about cognition, motivation and emotion, ability and personality, psychological activity and development of people, etc. The Chinese side turned it into psychological health education for college students, a course with Chinese characteristics, which involves a narrow range of psychological knowledge. In other words, some courses only keep the names, but the content remains the old Chinese subject. It is true for some professional courses. Since it is a cooperative program, we should understand and accept foreign quality courses. Sole localization is not the best way. With names but without contents, the curriculum doesn't fulfill China's original purpose of introducing foreign excellent educational resources in essence.

\section{Cultural Adaptation of the Faculty and Students}

As the main curriculum guide, the importance of teachers in the Chineseforeign cooperative program is self-evident. At the beginning, the curriculum was set by the professionals. However, they failed to fully anticipate the complexity of Sino-foreign cooperative education and the impact of cultural differences. Some courses require professional teachers with strong English skills. A majority of Chinese teachers are very responsible, willing to adjust their own teaching content according to the new syllabus, and actively cooperate with foreign teachers in course teaching. But after all, not all the teachers have a very good foreign language proficiency. When trying to learn foreign professional knowledge, they may have some problems in understanding some specific points caused by cultural differences or other factors. So, do the foreign teachers. According to the schedule, they should come to China for a short time, maybe only a month, to give lectures to Chinese students. They are given little time to adapt to cultural differences. Consequently, some problems arise, like Chinese students are not as active as foreign students, the teacher have no time to know about Chinese students and so on.

For students, the problem of their cultural adaptation firstly lies in the lack of cultural adaptation curriculum. Although they have intensive English learning courses, most of them focus on skills training instead of understanding the language and culture. There is only one course American culture involving a simple introduction of culture, but the session is not long enough for them to truly understand the real crosscultural communication content. Secondly, some students cannot adapt to the teaching method of Sino-foreign cooperative program. They get used to rely on teachers' explanations and answers rather than finish the tasks by themselves. In addition, they lack team work experience, showing little enthusiasm in cooperating with other students. Due to the pressure caused by intense curriculum, some students even show obvious reluctance in learning. Finally, students are uncertain about their future. Normally, Chinese students haven't no habit of planning their future in advance. They are hesitated about whether to study abroad or work at home, leading to a hasty decision when they become a senior and have to make the decision.

\section{SUGGESTIONS ON THE CURRICULUM OF SINO-AMERICAN NURSING PROGRAM}

In response to the various issues raised above, some suggestions for the improvement of Sino-foreign cooperative programs are put forward:

1). To increase cultural adaptation courses. Most students think it necessary to add more cultural adaptation courses. The General Introduction of United States, for example, can be provided. It helps develop students' understanding and respect for the culture in all aspects, like geography, politics, history, economy, society and customs, etc. Through systematic study, the students can deeply understand the cultural connotation and attach importance to the melting of culture and language curriculum. The course Intercultural Communication should be added to train students to examine the differences and conflicts between Chinese and western cultural values from various angles [4]. It may help to improve their ability to absorb foreign cultures, to cultivate their global consciousness, and eventually to avoid cross-cultural conflicts and cultural shocks.

2). To adjust the content of some courses. As mentioned above, the courses are not closely linked at home and abroad, and some of the courses are not practical enough. Therefore, it's essential for the management to have a clearer understanding of multicultural education. On the one hand, we should actively and reasonably utilize foreign excellent educational resources. We need to understand the syllabus and actual teaching contents of each other's curriculum, and at the same time, learn the other side's teaching methods. On the other hand, we should pay attention to absorb and digest when introducing curriculum and make localization according to students' actual demand and real level. Only when we integrate knowledge at home and abroad, combine internationalization with localization, can we develop proper Chinese-foreign cooperative teaching curriculum for Chinese students.

3). To enrich selective courses. More selective courses could be added to realize the combination of compulsory courses and selective courses to meet different needs of students as far as possible. The compulsory courses enable them to master basic knowledge and required skills to achieve the goal of cultivating talents in schools [2]. Selective courses meet the needs of different career planning and promote the development of students' personality. For example, students who intend to go abroad can choose more language-related courses and acculturation courses in order 
to prepare for future study. Students who want to work in China can choose more basic or practical courses, strengthen their practical ability and boost their prospects of landing a good job.

4). To enhance the building of the teaching team. The teaching staff is the guarantee of the smooth implementation of the curriculum [2]. First of all, we should strengthen the training of existing teachers and arrange professional teachers to study in cooperative colleges. On the one hand, these teachers can strengthen their fluency in using foreign languages. On the other hand, after learning and absorbing these professional knowledge, teachers will combine it with their existing professional knowledge and choose appropriate content to teacher to the students. This can not only improve the professional level of teachers themselves, but also help students to understand foreign professional knowledge more deeply [5]. In addition, language course teachers can also learn some basic professional courses. After acquiring some basic knowledge, they can go to the departments or hospitals to take practical training. In this way, language teachers are not limited to the transmission of language knowledge, they can teach more from a professional perspective to students. To summarize, the teachers can be trained into compound talents.

\section{CONCLUSION}

The implementation of Sino-American Nursing Program of HUCM and WSSU is generally good, but in detail there are many aspects needed to be improved. Although the original curriculum introduced some advanced courses from abroad, there are some problems of cultural adaptation when carried out in China. This cultural adaptation is not only reflected in the curriculum, but also in the students and teachers. The solution to the problems lies in the integration of new cultural elements. If we can handle the cultural differences and contradictions properly, we are bound to utilize the foreign high-quality educational resources and reap its benefits eventually.

\section{ACKNOWLEDGMENTS}

Teaching Research Project of Hubei University of Chinese Medicine of 2015 No. 2015B31 A Study of the Construction of General Education Curriculum System of Sino-Foreign Cooperative Undergraduate Programs from the Perspective of Cultural Adaptation

\section{REFERENCES}

[1] Ling, Z., Mingyong, Z. 2013. Research into the Course Development and Application of the Joint Educational Program in Higher Vocational College [J]. Journal of Wuhan Polytechnic, 12 (6), 37-41.

[2] Zheng, W. 2011. A Study of the Curriculum Setting of Sino-foreign Cooperative Project [D]. Zhejiang Normal University.

[3] Tian, C., Zaoming, M. 2014. Probing into the Curriculum Models in and Physical Foundation for General Education in U.S. countries [J]. Tsinghua Journal of Education, 35 (6), 85-92.

[4] Qing, H. 2011. English Selective Courses Aiming at Cultivating Students' Intercultural Communication Awareness and Competence in Sino-foreign Cooperative Project [J]. Journal of Inner Mongolia Normal University, 24 (5), 90-93.

[5] Wei, L. 2010. An Exploration and Practice of English Teaching in Sinoforeign Joint Program [J]. Journal of Anhui Agricultural University, 19 (2), 126-129. 